\title{
Tracking arrow squid movements with an automated acoustic telemetry system
}

\author{
Kate E. Stark ${ }^{1,2, *}$, George D. Jackson ${ }^{1}$, Jeremy M. Lyle ${ }^{2}$ \\ ${ }^{1}$ Institute of Antarctic and Southern Ocean Studies, University of Tasmania, Private Bag 77, Hobart, Tasmania 7001, Australia \\ ${ }^{2}$ Marine Research Laboratories, Tasmanian Aquaculture \& Fisheries Institute, University of Tasmania, Private Bag 49, \\ Hobart, Tasmania 7001, Australia
}

\begin{abstract}
This study investigated the movement, spatial usage and activity patterns of the arrow squid Nototodarus gouldi (Cephalopoda: Ommastrephidae) using an automated acoustic telemetry system. Sixty-four automated acoustic receivers were aligned as underwater 'curtains' across the entrances to bays and inlets around Storm Bay, southeastern Tasmania. N. gouldi were tagged with small uniquely coded transmitters and released. Twelve tagged squid were detected for up to $37 \mathrm{~d}$ over an area of more than $300 \mathrm{~km}^{2}$. Tagged squid moved widely between Storm Bay and the Derwent River, but none were detected moving into the adjoining bays or the D'Entrecasteaux Channel. Tagged squid appeared to move out of Storm Bay throughout the study period, suggesting a highly dynamic population. There was evidence of a relationship between level of activity and photoperiod, with visits to receivers being longer and more variable in duration in the night compared to the daytime. Schooling or group movement was not observed. Rates of movement between non-adjacent receivers varied widely with those over distances of $10 \mathrm{~km}$ or more, ranging from 0.09 to 0.52 mantle lengths per second (ML s${ }^{-1}$ ), and 1 instance of an average speed of $3.6 \mathrm{ML} \mathrm{s}^{-1}$ over $9.3 \mathrm{~km}$.
\end{abstract}

KEY WORDS: Ommastrephid squid · Acoustic telemetry · Tagging • Movement • Behaviour • Cephalopod · Tasmania

Resale or republication not permitted without written consent of the publisher

\section{INTRODUCTION}

The arrow squid Nototodarus gouldi (Cephalopoda: Ommastrephidae) is widespread across southern Australia and in northern New Zealand. Recent biological studies have shown that, in Australian waters, $N$. gouldi are genetically well-mixed (Triantafillos et al. 2004), live for less than $1 \mathrm{yr}$ and are multiple spawners, with hatching occurring year-round (McGrath \& Jackson 2002, Jackson et al. 2003). The species is a valuable by-catch of shelf and slope trawl fisheries and is the exclusive target of Australia's largest squid jig fishery, which occurs seasonally in waters off Victoria (Winstanley et al. 1983, Lynch 2004). There is also a sporadic jig fishery in inshore Tasmanian waters during the summer months, concentrated primarily off the southeast coast. Samples from this fishery have shown that female $N$. gouldi are mostly immature when they first move into coastal waters, but mature progressively throughout the Tasmanian summer (Willcox et al. 2001). The inshore movement in southeastern Tasmania is most likely related to feeding as females of this species must meet the cost of maturation with increased food consumption rather than through energy re-allocation (McGrath \& Jackson 2002). Similar feeding migrations are welldocumented for other Ommastrephid squid (Haimovici et al. 1998, Perez \& O'Dor 1998, Mokrin et al. 2002, Nigmatullin et al. 2002, Watanabe et al. 2004).

Nototodarus gouldi is the most important cephalopod resource in Australian waters, yet little is known about its ecology and nothing about its movement patterns. The biomass (based on fishery production) of $N$. gouldi in southeastern Tasmania varies greatly, both within and between years (Willcox et al. 2001), and movement, possibly in response to environmen- 
tal conditions, is thought to play a key role in shaping these patterns. Despite this, we have no understanding of the timing and nature of movement between inshore and offshore areas, how $N$. gouldi utilise the inshore environment, and how they behave with regard to schooling and activity patterns. With the development of electronic tagging systems, these issues can now be addressed with fewer logistical constraints than traditional tag recapture methods.

The use of acoustic tracking systems and archival data loggers has provided valuable insights into migration patterns (e.g. Block et al. 2001, Comeau et al. 2002), gene flow and dispersion (e.g. Moran et al. 2003), habitat preferences and home ranges (e.g. Parsons et al. 2003), and responses to physical and biological variability (e.g. Brill et al. 2002, Heupel \& Hueter 2002). However, few studies using this technology have been conducted on cephalopods. Most have focussed on behaviour and energetics over small spatial and temporal scales, employing radioacoustic positioning and telemetry systems (RAPT; O'Dor et al. 1994, Sauer et al. 1997, O'Dor 2002,
Aitken et al. 2005). Larger-scale movement and migration patterns are known to be important processes in cephalopod populations, but are usually implied from analyses of distribution, abundance and biological patterns (e.g. Hatfield \& Rodhouse 1994, Arkhipkin 2000). There has been very limited tag-recapture work (Nagasawa et al. 1993, Sauer et al. 2000, Markaida et al. 2005), active tracking (Nakamura 1993) or use of archival and pop-up satellite tags (TOPP; www.toppcensus. org).

The aims of this study were to investigate and describe the movement patterns of Nototodarus gouldi in southeastern Tasmania using an automated underwater acoustic tracking system (Vemco). The system comprises compact acoustic receivers, each containing a hydrophone and data recorder, and small tags that transmit a unique acoustic signal (Klimley et al. 1998, Voegeli et al. 1998). Receivers moored at specific locations continuously record the presence of any tag that moves into its detection radius, and thus movement pathways and spatial usage patterns can be derived.

\section{MATERIALS AND METHODS}

Study site. The study was carried out in Storm Bay and its associated bays, inlets and estuaries (Fig. 1). Storm Bay is a large shallow basin in southeast Tasmania. It has an area of more than $500 \mathrm{~km}^{2}$ and a maximum depth of $85 \mathrm{~m}$ (Clementson et al. 1989). The waters are mostly less than $50 \mathrm{~m}$ in depth and the bottom primarily sand, with occasional small patches of rocky reef.

Acoustic receivers. Sixty-four VR2 acoustic receivers (Vemco) were deployed within the study area. Each receiver was fastened to a vertical steel pole on a concrete mooring, approximately $1 \mathrm{~m}$ above the sea floor. Acoustic release mechanisms (Sub Sea Sonics) were attached to receivers deployed in deep water $(>20 \mathrm{~m})$; otherwise, divers were used for retrieval. Receivers were aligned equidistantly into 'curtains' across the entrances to several water bodies in the study area (Curtains B, C, D, E, F, G, H and I; Fig. 1). Receivers at $\mathrm{L}$ were not aligned in a single curtain but as 3 short lines perpendicular to the coastline (Fig. 1) and are referred to as 'Array' L. These receivers were
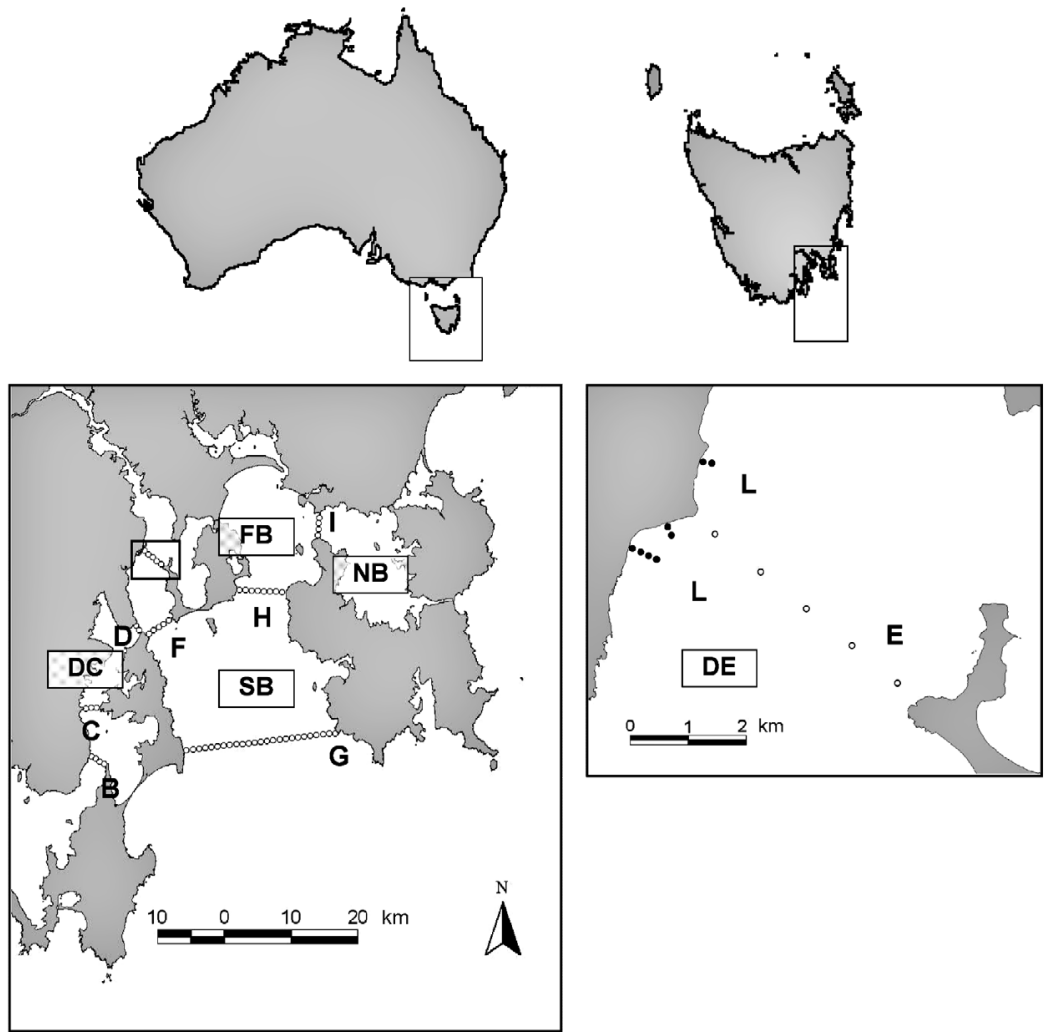

Fig. 1. Study area in southeast Tasmania, Australia. FB: Frederick Henry Bay; NB: Norfolk Bay; DC: D'Entrecasteaux Channel; SB: Storm Bay; DE: Derwent Estuary. Each unfilled circle represents 1 VR2 receiver. Receivers were aligned into 'curtains', which are labelled B to I, and 'Array' L. The boxed area is shown at greater resolution, displaying the arrangement of Curtains E (•) and L (O) 
originally deployed as part of another study, but are included here because arrow squid detections were recorded on them.

The depths of receivers ranged from 2 to $55 \mathrm{~m}$, and were placed on sand, silt or seagrass, although 1 receiver (E1) was on low profile reef. Receivers were spaced between 725 and $930 \mathrm{~m}$ apart within each curtain. Although not range-tested, a detection radius of between 365 and $465 \mathrm{~m}$ was required for full curtain coverage.

The receiver network was deployed in October 2002 but due to a lack of availability, squid were not tagged until January 2003. Most receivers were retrieved in early April 2003, although 1 receiver in Curtain $\mathrm{H}$ was removed earlier (21 March) after becoming entangled in a fishing net. The receivers in Array $L$ were not retrieved until May 2003 and a receiver in Curtain G was not retrieved until July 2003 due to difficulties in relocating it.

Acoustic transmitters. The transmitters used to tag arrow squid were V8SC-2H coded pingers (Vemco). The cylindrical transmitters are $30 \mathrm{~mm}$ in length, $9 \mathrm{~mm}$ in diameter, and weigh $3.1 \mathrm{~g}$ in water. They each transmit a unique pinging sequence at a frequency of $69 \mathrm{kHz}$, which is repeated after a random delay of between 20 and $60 \mathrm{~s}$. Battery life was rated at $87 \mathrm{~d}$. Transmitters were activated by soldering together the 2 activation wires and prepared for tagging by gluing a fine $1.10 \mathrm{~mm} \times 38 \mathrm{~mm}$ needle across the top of the transmitter. Squid were tagged with the transmitters 2 to $25 \mathrm{~d}$ after activation, the delay for some transmitters being due to unexpected difficulty in obtaining squid for tagging. Nototodarus gouldi were scarce and patchy during the 2002/03 summer; individuals were rarely captured at the same location and time as each other (Table 1). Thus, transmitter batteries were due to expire between 62 and $85 \mathrm{~d}$ after actual deployment.

Nototodarus gouldi were caught using jigs on hand lines and immediately placed in a tagging cradle. Dorsal mantle length (ML) was measured to the nearest centimetre and individuals were sexed where possible by noting the presence of hectocotylisation on arm IV. A minimum tagging size of $18 \mathrm{~cm}$ ML was set, ensuring the transmitter was less than $2.5 \%$ of the total body weight in all individuals (Willcox et al. 2001).

The transmitter was placed just inside the ventral mantle of the squid, the needle piercing through the mantle to the outside where it was crimped in place and cut off. Silicon washers were used to prevent the transmitter and crimp from abrading the squids' mantle (after O'Dor et al. 1994). After tagging, squid were injected at the base of the arms with 1 to $2 \mathrm{ml}$ of the antibiotic tetracycline, dissolved to saturation in seawater (approx. $6 \mathrm{mg} \mathrm{ml}^{-1}$ ). Squid were held gently in the water and released when deemed to have recov-
Table 1. Nototodarus gouldi. Details of tagged squid. Bold text indicates tags that were detected during the study. ML: mantle length $(\mathrm{cm})$. Sex: male $(\mathrm{M})$, female $(\mathrm{F})$ or not determined (U). Brackets indicate squid tagged and released together (similar time and location)

\begin{tabular}{|c|c|c|c|c|}
\hline Tag no. & $\begin{array}{c}\text { Date } \\
2003(\mathrm{~d} / \mathrm{m})\end{array}$ & Time & ML (cm) & Sex \\
\hline 78 & $11 / 01$ & 08:45 & 21 & $\mathbf{U}$ \\
\hline 75 & $11 / 01$ & 08:56 & 22 & $\mathbf{U}$ \\
\hline 88 & $11 / 01$ & $10: 28$ & 22 & $\mathrm{U}$ \\
\hline 69 & $16 / 01$ & 05:59 & 25 & $\mathbf{M}$ \\
\hline 63 & $16 / 01$ & $06: 50$ & 20 & $\mathbf{F}$ \\
\hline 65 & 28/01 & $22: 31$ & 20 & $\mathrm{U}$ \\
\hline 84 & $28 / 01$ & $23: 25$ & 22 & $\mathbf{F}$ \\
\hline 86 & $29 / 01$ & 01:23 & 18 & F \\
\hline 68 & $29 / 01$ & 01:32 & 23 & F \\
\hline 62 & 29/01 & 02:55 & 24 & F \\
\hline 81 & 29/01 & 04:15 & 19 & $\mathbf{F}$ \\
\hline 67 & 03/02 & $08: 16$ & 19 & $\mathrm{M}$ \\
\hline 87 & 03/02 & 08:34 & 25 & $\mathbf{F}$ \\
\hline 71 & $03 / 02$ & 09:02 & 23 & $\mathbf{M}$ \\
\hline 76 & 03/02 & 09:03 & 19 & $\mathrm{U}$ \\
\hline 72 & 03/02 & 09:40 & 20 & $\mathrm{~F}$ \\
\hline 77 & 03/02 & 09:41 & 20 & $\mathrm{U}$ \\
\hline 70 & 03/02 & 09:42 & 21 & M \\
\hline 66 & $03 / 02$ & $09: 45$ & 20 & M \\
\hline 79 & $03 / 02$ & 09:47 & 20 & $\mathbf{U}$ \\
\hline 64 & $03 / 02$ & 09:54 & 21 & $\mathbf{M}$ \\
\hline 73 & $03 / 02$ & 09:59 & 20 & $\mathbf{M}$ \\
\hline 90 & 03/02 & $10: 29$ & 20 & M \\
\hline
\end{tabular}

ered sufficiently (when jetting water strongly). Squid were out of the water during the tagging process for less than 1 min.

Analyses. Data were downloaded as text files from the VR2s and then transferred to an MS-Access database. Individual movement tracks were plotted in ArcView 3.2 using the Animal Movement extension point-to-polyline tool (Hooge \& Eichenlaub 1997). Spatial usage was examined by comparing detection data between receivers and curtains. No statistical tests were conducted due to the spatial autocorrelation of the data. The coverage of each curtain was calculated as the proportion of a straight line running along a curtain (through each receiver) that was within detection range, assuming receiver detection radii of $400 \mathrm{~m}$. This is probably a conservative estimate, given that detection ranges have been found to be at least $400 \mathrm{~m}$ over a range of depths and habitats (Arendt et al. 2001, Heupel \& Hueter 2001, Comeau et al. 2002, Welch et al. 2003).

Activity patterns were inferred by the number of visit events. A visit event for a particular transmitter was defined as a continuous string of observations at a curtain, where there was no more than 30 min between consecutive observations. Thus, a single visit event could comprise only 1 observation at 1 receiver, 
or a large number of observations at several receivers within a curtain. Visit event duration was the time between the first and last detection of a visit event, plus $1 \mathrm{~min}$. This ensured that visit events of just $1 \mathrm{ob}-$ servation had a duration of $1 \mathrm{~min}$, the maximum possible time between pulse transmissions. The distribution of visit event durations was highly skewed and could not be normalised by transformation, so the median and median absolute deviation (MAD) (Quinn \& Keough 2002) were used as location and spread descriptors.

Time, distance and speed (rate of movement) were calculated for movements recorded between nonadjacent receivers. Time was the period between the last detection at one receiver and the first detection at the next non-adjacent receiver. Distance was measured between the positions of the 2 relevant receivers ( $\mathrm{km}$ and ML specific to the squid in question).

Associations between tagged squid were investigated by arranging all observations into time intervals of (1) 20 and (2) $60 \mathrm{~min}$. Squid were considered to be associated with one another if detected at the same location within the same time interval (i.e. a paired or group detection).

\section{RESULTS}

\section{Acoustic receivers and transmitters}

Twenty-three Nototodarus gouldi were tagged with transmitters and released over a $4 \mathrm{wk}$ period between mid-January and early February 2003 (Table 1). All squid were released within the northern part of Storm Bay (between Curtains F, G and H), except for 2 that were released near the mouth of the Derwent River, north of Curtain F. Of the tagged squid, 8 were female, 8 were male, and sex was not determined for 7 . They ranged in size between 18 and $25 \mathrm{~cm} \mathrm{ML}$ and all appeared to recover rapidly from the tagging procedure.

Two of the receivers in Curtain $\mathrm{E}$ and one in Array L were not recovered due to detachment from their moorings. Another receiver, in Curtain G, was recovered but had been irretrievably damaged, so effectively a maximum of 60 receivers were present at any stage during the study and this number declined as the study progressed (Fig. 2). One receiver had a memory failure while deployed (Curtain F), and for 2 others, the data did not download completely after retrieval (Curtain G). Thus, the end date for these 3 receivers is not the retrieval date, but rather the date of the last recorded detection (F: 23 January, G: 22 January and 25 February).

Overlap of receiver ranges was evident for Curtains F, G and $\mathrm{H}$, as some transmitter signals were detected at the same time at adjacent receivers within these curtains. Despite this, the loss and failure of receivers in Curtains E, F and G means they could not have full coverage for at least some of the study duration.

\section{Detections}

Twelve of the tagged squid ( $52 \%$ ) were detected at least once during the study (Table 2). This group comprised 5 females, 4 males and 3 of unknown sex. They ranged in size from 19 to $25 \mathrm{~cm}$, thus reflecting the size structure and sex ratio of the tagged sample (see Table 1). Neither the release date nor the location of release appeared to have any bearing on whether a squid was detected or not.

Each of the 12 detected squid accounted for between 23 and 1832 observations (Table 2), representing between 1 and 24 visit events. Squid were first detected either on the day they were released or up to $17 \mathrm{~d}$ later (Table 2). The number of separate days on which individual squid were detected ranged between 1 and $11 \mathrm{~d}$, over periods of 2 to $37 \mathrm{~d}$ (i.e. from the date of release to the date of last detection). There were no detections recorded after 5 March 2003 (Fig. 2), despite the fact that more than 50 receivers were present in the study area until the end of March and transmitter batteries should not have expired until early April.

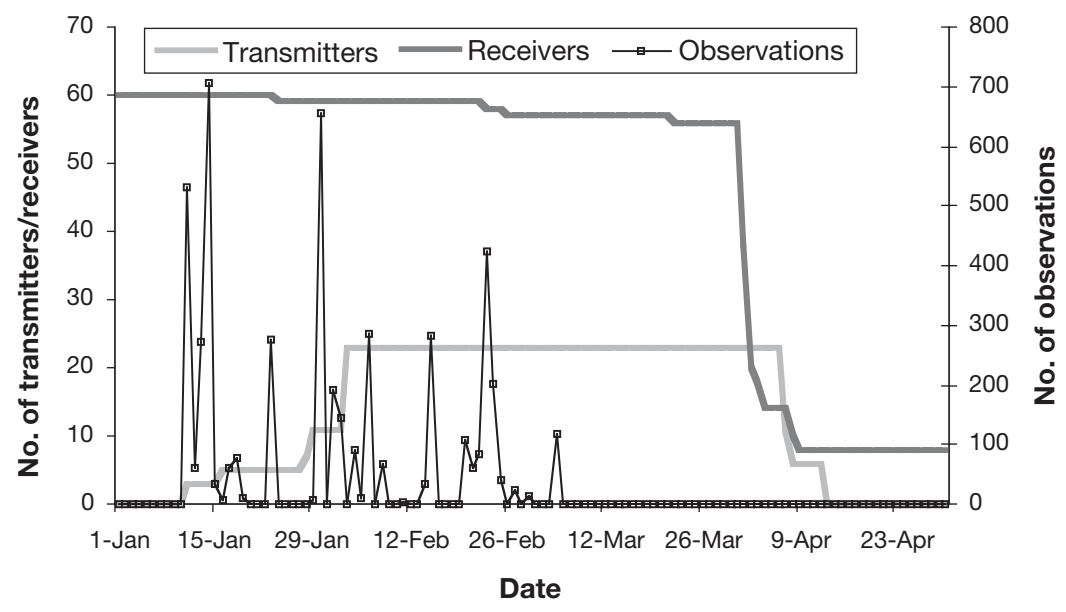

Fig. 2. Nototodarus gouldi. Number of active receivers and transmitters, and number of observations recorded by date 
Table 2. Nototodarus gouldi. Details of detected transmitters: the number of days between release and 1st detection; the number of actual days on which each squid was detected; the number of days from release to last detection; the number of observations recorded; the number of curtains visited; and the number of receivers visited

\begin{tabular}{|lcccccc|}
\hline $\begin{array}{l}\text { Trans- } \\
\text { mitter }\end{array}$ & $\begin{array}{c}\text { Days to } \\
\text { 1st } \\
\text { detection }\end{array}$ & $\begin{array}{c}\text { No. of } \\
\text { days } \\
\text { detected }\end{array}$ & $\begin{array}{c}\text { Period (d) } \\
\text { detected }\end{array}$ & $\begin{array}{c}\text { No. of } \\
\text { obser- } \\
\text { vations }\end{array}$ & $\begin{array}{c}\text { No. of } \\
\text { curtains }\end{array}$ & $\begin{array}{c}\text { No. of } \\
\text { receivers }\end{array}$ \\
\hline 78 & 0 & 6 & 13 & 1832 & 3 & 12 \\
75 & 0 & 7 & 9 & 132 & 1 & 1 \\
69 & 16 & 2 & 24 & 242 & 2 & 4 \\
63 & 2 & 1 & 3 & 71 & 1 & 1 \\
84 & 2 & 11 & 37 & 1219 & 3 & 15 \\
62 & 7 & 7 & 32 & 138 & 3 & 4 \\
81 & 0 & 2 & 2 & 593 & 2 & 6 \\
87 & 17 & 1 & 18 & 23 & 1 & 1 \\
71 & 12 & 1 & 13 & 284 & 1 & 2 \\
79 & 1 & 1 & 2 & 54 & 1 & 4 \\
64 & 1 & 1 & 2 & 36 & 1 & 2 \\
73 & 3 & 1 & 4 & 265 & 1 & 2 \\
Mean & 5.1 & 3.4 & 13.3 & 407.4 & 1.7 & 4.5 \\
Total & & 30 & & 4889 & 6 & 35 \\
\hline
\end{tabular}

at Curtain H (Transmitter 73) was there for approximately $3.5 \mathrm{~h}$, but as it was not detected again, it is impossible to determine whether it continued into Frederick Henry Bay or moved back into Storm Bay.

\section{Spatial usage}

Tagged squid were detected at 6 of the 9 curtains (Table 4). There were no observations recorded at Curtains B, C or I, indicating that the tagged squid did not move down the D'Entrecasteaux Channel, or into Norfolk Bay. The 3 most visited curtains, in terms of number of tagged squid and number of observations, were G, F and E, which were also the curtains with the poorest coverage due to missing or failed receivers (Table 4). Most squid visited few receivers within a curtain (Table 2); however, the particular receivers visited varied among squid and thus, transmitters were detected at at least two-thirds of the active receivers within each curtain (excluding Curtains D and $\mathrm{H}$ which only detected 1 transmitter each; Table 4). Observations were recorded at receivers covering a wide range of depths ( 2 to $>50 \mathrm{~m}$ ) and distances from the shoreline $(0.6$ to $>10 \mathrm{~km})$.

Receivers that recorded observations were generally spread across the curtains; however, the number of observations recorded and transmitters detected varied greatly among receivers within curtains. Two adjacent receivers in both Curtains $\mathrm{E}$ and $\mathrm{F}$ recorded the most observations of all receivers, and several squid returned to these same receivers after spending time elsewhere (Fig. 3). The other active receivers in these curtains had comparatively few or no observations. There were no particular receivers that dominated Curtain $G$ in terms of the number of observations recorded, although squid were not detected at the receivers closest to the shore of the Tasman Peninsula and Bruny Island.

\section{Activity patterns}

The duration of visit events was highly skewed, with $30 \%$ of visit events only 1 min in length (the minimum possible visit event duration by definition), and $70 \%$ less than $1 \mathrm{~h}$. This suggests that squid were either often near the detection limit of receivers, or that they were passing through a narrow area of overlap. The longest did not travel far or spend long there. A squid detected 
Table 3. Nototodarus gouldi. Curtains at which each squid was detected, by date. Square box indicates date of tag and release. ${ }^{*}$ : last detection; -: days between detections

\begin{tabular}{|c|c|c|c|c|c|c|c|c|c|c|c|c|c|}
\hline \multirow[t]{2}{*}{ Month } & \multirow[t]{2}{*}{ Day } & \multicolumn{12}{|c|}{ Transmitter } \\
\hline & & 78 & 75 & 69 & 63 & 84 & 62 & 81 & 87 & 71 & 79 & 64 & 73 \\
\hline January & 10 & & & & & & & & & & & & \\
\hline & 11 & $\mathrm{~F}$ & $\mathrm{~F}$ & & & & & & & & & & \\
\hline & 12 & $\mathrm{~F}$ & - & & & & & & & & & & \\
\hline & 13 & L & F & & & & & & & & & & \\
\hline & 14 & $\mathrm{E}, \mathrm{L}$ & F & & & & & & & & & & \\
\hline & 15 & - & F & & & & & & & & & & \\
\hline & 16 & E & - & $\square$ & $\square$ & & & & & & & & \\
\hline & 17 & - & F & - & - & & & & & & & & \\
\hline & 18 & - & F & - & $\mathrm{G}^{*}$ & & & & & & & & \\
\hline & 19 & - & $\mathrm{F}^{*}$ & - & & & & & & & & & \\
\hline & 20 & - & & - & & & & & & & & & \\
\hline & 21 & - & & - & & & & & & & & & \\
\hline & 22 & - & & - & & & & & & & & & \\
\hline & 23 & $\mathrm{~F}^{*}$ & & - & & & & & & & & & \\
\hline & 24 & & & - & & & & & & & & & \\
\hline & 25 & & & - & & & & & & & & & \\
\hline & 26 & & & - & & & & & & & & & \\
\hline & 27 & & & - & & & & & & & & & \\
\hline & 28 & & & - & & $\square$ & & & & & & & \\
\hline & 29 & & & - & & - & & $\mathbf{L}$ & & & & & \\
\hline & 30 & & & - & & F & -1 & $\overline{\mathrm{E}, \mathrm{L}}$ * & & & & & \\
\hline & 31 & & & - & & - & - & & & & & & \\
\hline February & 1 & & & F & & E & - & & & & & & \\
\hline & 2 & & & - & & F & - & & & & & & \\
\hline & 3 & & & - & & - & - & & $\square$ & $\square$ & $\square$ & $\square$ & $\square$ \\
\hline & 4 & & & - & & - & - & & - & - & $\mathrm{G}^{*}$ & $\overline{\mathrm{G}}^{*}$ & - \\
\hline & 5 & & & - & & - & F & & - & - & & & - \\
\hline & 6 & & & - & & - & F & & - & - & & & $\mathrm{H}^{*}$ \\
\hline & 7 & & & - & & - & - & & - & - & & & \\
\hline & 8 & & & $\mathrm{G}^{*}$ & & - & - & & - & - & & & \\
\hline & 9 & & & & & - & - & & - & - & & & \\
\hline & 10 & & & & & - & - & & - & - & & & \\
\hline & 11 & & & & & - & F & & - & - & & & \\
\hline & 12 & & & & & - & - & & - & - & & & \\
\hline & 13 & & & & & - & - & & - & - & & & \\
\hline & 14 & & & & & G & - & & - & - & & & \\
\hline & 15 & & & & & - & - & & - & $\mathrm{G}^{*}$ & & & \\
\hline & 16 & & & & & - & - & & - & & & & \\
\hline & 17 & & & & & - & - & & - & & & & \\
\hline & 18 & & & & & - & - & & - & & & & \\
\hline & 19 & & & & & - & - & & - & & & & \\
\hline & 20 & & & & & G & - & & $\mathrm{G}^{*}$ & & & & \\
\hline & 21 & & & & & G & - & & & & & & \\
\hline & 22 & & & & & G & - & & & & & & \\
\hline & 23 & & & & & G & - & & & & & & \\
\hline & 24 & & & & & G & $\mathrm{D}, \mathrm{F}$ & & & & & & \\
\hline & 25 & & & & & G & F & & & & & & \\
\hline & 26 & & & & & - & - & & & & & & \\
\hline & 27 & & & & & - & F & & & & & & \\
\hline & 28 & & & & & - & - & & & & & & \\
\hline March & 1 & & & & & - & $\mathbf{G}^{*}$ & & & & & & \\
\hline & 2 & & & & & - & & & & & & & \\
\hline & 3 & & & & & - & & & & & & & \\
\hline & 4 & & & & & - & & & & & & & \\
\hline & 5 & & & & & $\mathrm{G}^{*}$ & & & & & & & \\
\hline & 6 & & & & & & & & & & & & \\
\hline & 7 & & & & & & & & & & & & \\
\hline & 8 & & & & & & & & & & & & \\
\hline & 9 & & & & & & & & & & & & \\
\hline & 10 & & & & & & & & & & & & \\
\hline
\end{tabular}

visit event was Transmitter 78 at Curtain F for $8.7 \mathrm{~h}$. Curtain G and Array L both had a similar median visit event duration of just over $30 \mathrm{~min}$, while the median for Curtains D and F was only around 17 min. Curtain E had a median of just $10.5 \mathrm{~min}$, and for Curtain $\mathrm{H}$ there was only 1 visit event (Transmitter 73), $3.5 \mathrm{~h}$ long (Table 4).

Over all receivers in all curtains except Curtain $G$, $87 \%$ of visit events occurred in the first $10 \mathrm{~d}$ after an individual was tagged and released (Table 4). At Curtain G, however, the majority of transmitters were detected after at least $10 \mathrm{~d}$ at liberty, and these detections tended to be towards the end of the study, regardless of the date of tag and release (Table 3). At Curtain G, $80 \%$ of visit events occurred more than $30 \mathrm{~d}$ after the start of the study.

The number of visit events detected varied throughout the day without any clear pattern associated with photoperiod. The median duration per visit event, however, was highly variable after sunset and before sunrise (21:00 till 06:00 h) and relatively low during daylight hours (Fig. 4).

There were 19 trips between non-adjacent receivers by 6 of the detected squid. The longest distance travelled between consecutive receiver detections was $28.6 \mathrm{~km}$, although half of the distances travelled were less than $3.5 \mathrm{~km}$ (Table 5). Sixty-eight percent of the trips were less than $2 \mathrm{~d}$ in duration, although they ranged up to $12.3 \mathrm{~d}$. There was large variability in the calculated speed of straight-line travel, from 0.003 to $1.489 \mathrm{~m} \mathrm{~s}^{-1}$, or 0.01 to $7.84 \mathrm{ML} \mathrm{s}^{-1}$. Shorter distances had more variable speeds, while trips of $10 \mathrm{~km}$ or more never had speeds greater than $0.12 \mathrm{~m} \mathrm{~s}^{-1}$ or $0.5 \mathrm{ML} \mathrm{s}^{-1}$ (Table 5).

Only 2 transmitters were detected at the same receiver within the same 20 min time interval. Transmitters 75 and 78 were both detected over a $2 \mathrm{~h}$ period at Curtain $\mathrm{F}$, less than $1 \mathrm{~h}$ after being tagged. They both remained in the general area of Curtains E, F and Array L for a further $8 d_{\text {; }}$ however, the only time during this period that they were both detected within the same 20 min time interval, they were at different curtains, at least $10 \mathrm{~km}$ apart (Table 3). No other pairs or groups of transmitters were detected at the same receiver in the same time interval, even when the time interval was increased to $60 \mathrm{~min}$. However, Transmitters 64 and 79 were detected at different receivers in Curtain G on 4 February, the day after they were both tagged (Table 3 ). These 2 pairs of transmitters (75 and 78 , and 64 and 79) were the only squid detected together throughout the study. In both cases, they were squid tagged and released together. Other groups of squid were tagged and released together but they were not detected during the study (e.g. Transmitters 68 and 86, Table 1). 

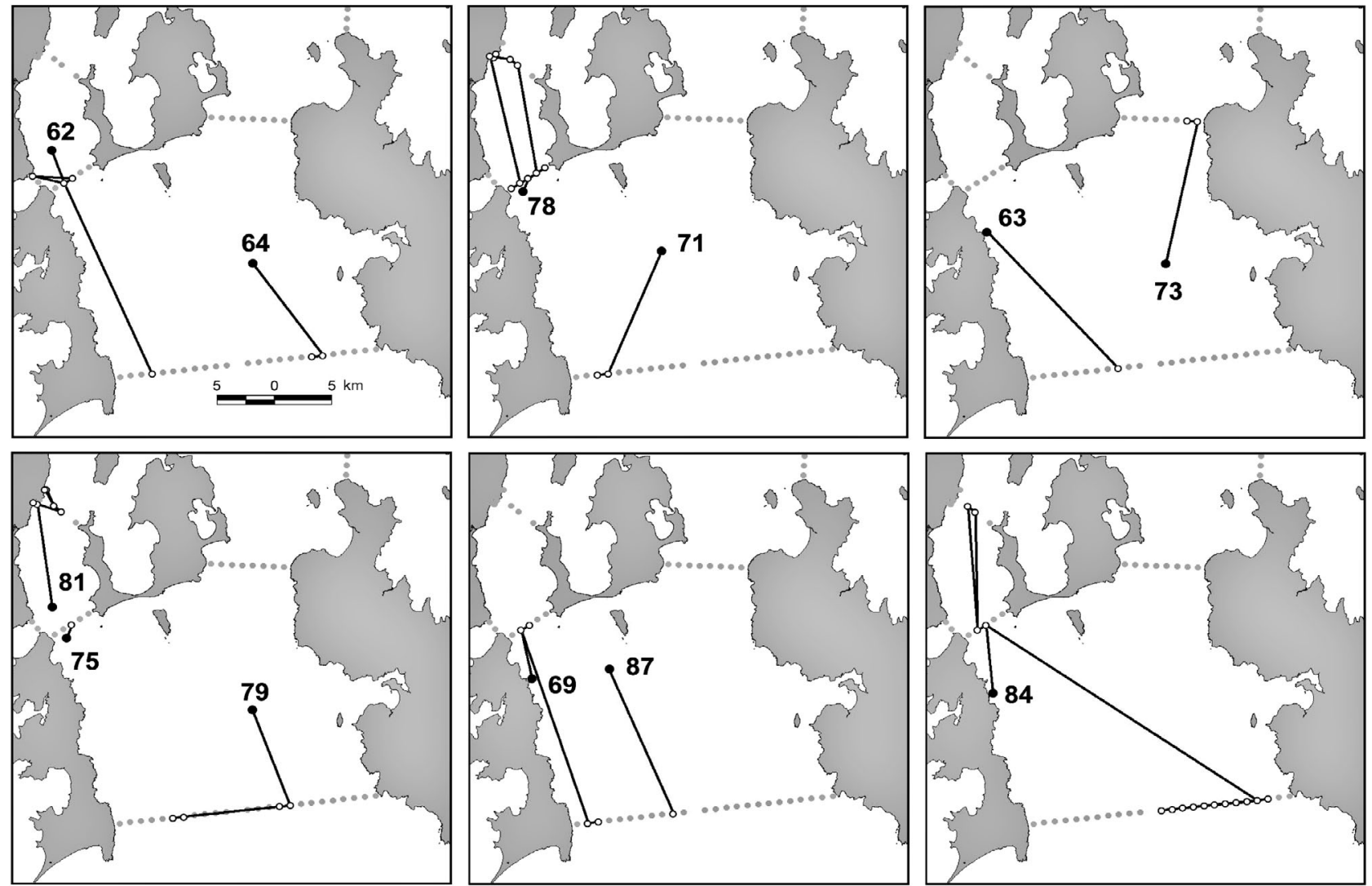

Fig. 3. Nototodarus gouldi. Movement tracks for the 12 detected squid. $\bullet$ : point of tag and release, number refers to the transmitter number; O: receivers where the animal was detected; : the straight-line track between receivers. Grey circles are all active receivers

\section{DISCUSSION}

A significant finding of this research relates to the implied movement of individuals away from the study area. Two-thirds of the tracked squid were last detected at Curtain G, across the entrance to Storm Bay. Although the design of the receiver network precludes determination of the movement direction (see below), the fact that receivers and transmitters were active for an extensive period after the final detections at Curtain G supports the notion that the squid moved out of the study area to other coastal or deeper shelf waters. It is possible that other tagged squid may have moved out of the study area without being detected. Three receivers failed while deployed within Curtain G and it is possible that gaps may have existed elsewhere. Without extensive range testing, we cannot be certain of the precise level of curtain coverage during the study. However, with an as- sumed detection range of $400 \mathrm{~m}$, extrapolation of the numbers of squid observed moving through Curtain G to that expected with complete coverage would account for just 1 or 2 of the undetected squid. Those squid that were never detected most likely remained within the

Table 4. Nototodarus gouldi. For each curtain, the number of tagged squid (i.e. transmitters) detected, observations recorded, the number of receivers with observations/the maximum number of active receivers, the proportion of coverage by the curtain (assuming a $400 \mathrm{~m}$ detection radius), the number of visit events and median visit duration $(\mathrm{h})$, with median absolute deviation (MAD) in parentheses. The coverage for Curtains $\mathrm{F}$ and $\mathrm{G}$ is a range as some receivers did not function for the full duration of the study

\begin{tabular}{|lrrcccc|}
\hline Curtain & Squid & $\begin{array}{c}\text { Obser- } \\
\text { vations }\end{array}$ & Receivers & Coverage & $\begin{array}{c}\text { Visit } \\
\text { events }\end{array}$ & $\begin{array}{c}\text { Median visit } \\
\text { event duration }\end{array}$ \\
\hline B & 0 & 0 & $0 / 4$ & 1.00 & 0 & \\
C & 0 & 0 & $0 / 3$ & 1.00 & 0 & \\
D & 1 & 18 & $1 / 2$ & 1.00 & 2 & $0.28(0.26)$ \\
E & 3 & 880 & $2 / 3$ & 0.62 & 11 & $0.18(0.16)$ \\
F & 5 & 1491 & $5 / 5$ & $0.75-0.91$ & 46 & $0.30(0.28)$ \\
G & 8 & 1534 & $18 / 24$ & $0.76-0.83$ & 30 & $0.53(0.52)$ \\
H & 1 & 265 & $2 / 8$ & 0.87 & 1 & 3.54 \\
I & 0 & 0 & $0 / 4$ & 0.91 & 0 & \\
L & 2 & 701 & $7 / 7$ & & 7 & $0.58(0.49)$ \\
\hline
\end{tabular}




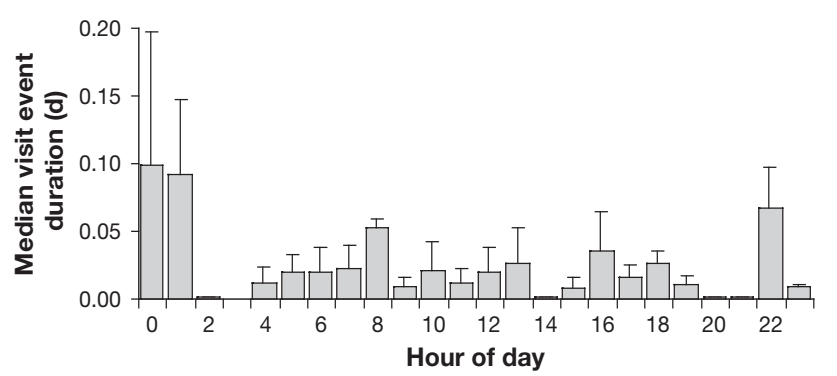

Fig. 4. Nototodarus gouldi. The median visit event duration (plus median absolute deviation) by hour of day

confines of Storm Bay, never moving into the detection range of Curtains $F, H$ or $G$, or were subject to posttagging mortality or tag loss.

It is difficult to interpret the relationship between individual movements out of the study area and the dynamics of the whole population as the year of the study was a poor one for Nototodarus gouldi in southern Tasmania. The available biomass was very low and as such, there was little commercial fishing, with catches of just $2 \mathrm{t}$ taken in 2002/03, the lowest catch in $10 \mathrm{yr}$ (Lyle 2003). Without commercial fishery or survey data, we cannot relate the observed movement patterns to the distribution and persistence of the population in Storm Bay over the study period. However, the timing of movement out of Storm Bay seen in this study is consistent with that evidenced by the fishery in previous years (1998/99, 1999/00, 2000/01), for which considerable data are available (Willcox et al. 2001). In general, commercial catches declined through February, and were very small by March. The movement of tagged squid in our study suggests that this decline in catch may be consistent with squid leaving the Storm Bay area, with most tagged individuals moving to the outer curtain (G) during February.

Movement out of the study area was not in any way synchronous, with individuals apparently leaving over an extended time period, suggesting a dynamic population whose composition changes throughout the inshore summer season. Although the movement dynamics may differ during periods of high abundance (as the variables influencing the abundance may also affect the population level patterns of residency), the patterns seen during this study have important implications from a fishery and ecosystem management perspective as it suggests that the decline in commercial catches in late summer is not entirely due to localised fishing effects, but is influenced by emigration too. The complexity of separating the effects of migration from the effects of commercial catches adds to the difficulty of assessing the resource (Basson et al. 1996).

There was no evidence of tagged squid moving from Storm Bay or the Derwent Estuary into the D'Entrecasteaux Channel. Nototodarus gouldi are known to utilise the Channel, having been caught in large numbers by recreational fishers in previous years (e.g. 1999/00; J. M. Lyle pers obs.), and the connectivity of these areas is of particular interest as the Channel is closed to commercial fishing and is perceived as a

Table 5. Nototodarus gouldi. The distance ( $\mathrm{km}$ and mantle length, ML), time (min) and speed ( $\mathrm{m} \mathrm{s}^{-1}$ and ML s${ }^{-1}$ ) of travel recorded between non-adjacent receivers

\begin{tabular}{|c|c|c|c|c|c|c|c|c|}
\hline Transmitter & $\begin{array}{l}\text { Date } 2003(\mathrm{~d} / \mathrm{m}) \\
\text { start }\end{array}$ & $\begin{array}{l}\text { Curtain } \\
\text { start }\end{array}$ & $\begin{array}{l}\text { Curtain } \\
\text { end }\end{array}$ & $\begin{array}{l}\text { Distance } \\
(\mathrm{km})\end{array}$ & $\begin{array}{l}\text { Time } \\
\text { (min) }\end{array}$ & $\begin{array}{l}\text { Speed } \\
\left(\mathrm{m} \mathrm{s}^{-1}\right)\end{array}$ & $\begin{array}{l}\text { Distance } \\
\left(\mathrm{ML} \times 10^{4}\right)\end{array}$ & $\begin{array}{c}\text { Speed } \\
\left(\mathrm{ML} \mathrm{s}^{-1}\right)\end{array}$ \\
\hline 62 & $05 / 02$ & $\mathrm{~F}$ & D & 2.8 & 294.4 & 0.003 & 1.16 & 0.01 \\
\hline 62 & $24 / 02$ & D & $\mathrm{F}$ & 3.4 & 9.2 & 0.104 & 1.43 & 0.43 \\
\hline 62 & $27 / 02$ & $\mathrm{~F}$ & G & 19.2 & 44.0 & 0.121 & 8.00 & 0.50 \\
\hline 69 & $01 / 02$ & $\mathrm{~F}$ & G & 18.7 & 164.6 & 0.032 & 7.50 & 0.13 \\
\hline 78 & $12 / 01$ & F & L & 12.0 & 35.7 & 0.094 & 5.73 & 0.45 \\
\hline 78 & $14 / 01$ & $\mathrm{~L}$ & E & 1.8 & 0.5 & 1.001 & 0.86 & 4.77 \\
\hline 78 & $16 / 01$ & $\mathrm{E}$ & $\mathrm{F}$ & 10.1 & 155.3 & 0.018 & 4.80 & 0.09 \\
\hline 79 & $04 / 02$ & G & $\mathrm{G}$ & 9.3 & 3.5 & 0.732 & 4.66 & 3.66 \\
\hline 81 & $29 / 01$ & $\mathrm{~L}$ & $\mathrm{E}$ & 2.6 & 2.6 & 0.277 & 1.34 & 1.46 \\
\hline 81 & $30 / 01$ & $\mathrm{E}$ & L & 1.7 & 2.4 & 0.196 & 0.90 & 1.03 \\
\hline 81 & $30 / 01$ & E & $\mathrm{L}$ & 1.7 & 0.8 & 0.604 & 0.90 & 3.18 \\
\hline 81 & $30 / 01$ & $\mathrm{~L}$ & E & 1.6 & 0.3 & 1.489 & 0.87 & 7.84 \\
\hline 84 & $30 / 01$ & $\mathrm{~F}$ & E & 11.5 & 36.6 & 0.087 & 5.21 & 0.40 \\
\hline 84 & $01 / 02$ & $\mathrm{E}$ & $\mathrm{F}$ & 10.9 & 26.5 & 0.114 & 4.96 & 0.52 \\
\hline 84 & $02 / 02$ & $\mathrm{~F}$ & $\mathrm{G}$ & 28.6 & 284.5 & 0.028 & 13.00 & 0.13 \\
\hline 84 & $14 / 02$ & $\mathrm{G}$ & G & 2.8 & 137.7 & 0.006 & 1.27 & 0.03 \\
\hline 84 & $22 / 02$ & $\mathrm{G}$ & $\mathrm{G}$ & 1.9 & 27.3 & 0.019 & 0.85 & 0.09 \\
\hline 84 & $23 / 02$ & $\mathrm{G}$ & $\mathrm{G}$ & 1.9 & 1.9 & 0.269 & 0.85 & 1.22 \\
\hline 84 & $25 / 02$ & $\mathrm{G}$ & $\mathrm{G}$ & 8.4 & 185.0 & 0.013 & 3.81 & 0.06 \\
\hline
\end{tabular}


'refuge' area, particularly in years of high fishing intensity. Our data suggest that either there was limited mixing of $N$. gouldi between the Channel and its adjacent waters (the Derwent Estuary and Storm Bay), or that the mixing was primarily unidirectional, with the Channel acting as a passageway for squid into the adjacent inshore waters, but not vice versa. Alternatively, $N$. gouldi may not have utilised the Channel at all during the study. Unfortunately, we have no information on the availability of $N$. gouldi in the D'Entrecasteaux Channel during the study period, nor on the connectivity of these water bodies in years when the biomass was high. Again, it is feasible that factors influencing the low inshore biomass may have also affected the patterns of residency in the study area. The environmental and/or prey conditions may only have been suitable in some areas, and not in the Channel during the study. Alternatively, it may be simply that sample sizes were insufficient to detect movement into all areas.

Nototodarus gouldi made use of a large part of the remaining study area, with several individuals moving extensively between curtains in the Derwent Estuary and Storm Bay. Some individual receivers in the lower Derwent Estuary region had notably more detections from more tagged squid, implying that they may have been within a passageway or frequently used route between the Derwent River and Storm Bay, or may have been desirable areas for other reasons, such as concentration of prey. These observations may have been influenced by the tag and release position, though it was noted that several individuals returned to these same receivers on multiple occasions. Further research coupling $N$. gouldi movement and spatial usage to small-scale environmental conditions, particularly prey density (e.g. Reid \& Hindell 2000, Heupel \& Hueter 2002) would be of value, particularly if conducted over seasons of contrasting abundances.

Rates of movement varied greatly, particularly over short distances. Half the trips measured were less than $0.5 \mathrm{ML} \mathrm{s}^{-1}$ and approximately $80 \%$ were less than $1.5 \mathrm{ML} \mathrm{s}^{-1}$. In general, speeds greater than this (including the maximum calculated, $7.8 \mathrm{ML} \mathrm{s}^{-1}$ ) were between receivers placed less than $2 \mathrm{~km}$ apart and were, therefore, greatly influenced by the fact that the calculations do not take into account the detection radius of each receiver. If the detection radius is, for example, $500 \mathrm{~m}$, the difference in the distance between the transmitters when detected and that estimated by receiver placements could be up to $1 \mathrm{~km}$, which has significant influence on straight-line speeds calculated over short distances.

Rates of movement calculated over $10 \mathrm{~km}$ or more ranged from 0.09 to $0.52 \mathrm{ML} \mathrm{s}^{-1}$; however, there was 1 instance of an average speed of $3.6 \mathrm{ML} \mathrm{s}^{-1}$ over
$9.3 \mathrm{~km}$ by Transmitter 79 moving between receivers G10 and G20. This movement was clearly not straightline as the squid was not detected at the receivers in-between and is, therefore, a minimum. Maximum speeds of another ommastrephid squid, Ommastrephes bartramii, determined by active tracking, were only $0.5 \mathrm{ML} \mathrm{s}^{-1}$ while on spawning grounds (Nakamura 1993) and $0.8 \mathrm{ML} \mathrm{s}^{-1}$ when migrating to the spawning grounds (Yoshida et al. 1990), whereas tag recapture studies of Todarodes pacificus recorded travelling at speeds of up to $2.14 \mathrm{~m} \mathrm{~s}^{-1}$ (Araya 1967 cited in Nagasawa et al. 1993). Assuming a maximum ML of $50 \mathrm{~cm}$ (Roper et al. 1984), this is equivalent to 4.3 $\mathrm{ML} \mathrm{s}^{-1}$. High-speed travel is clearly feasible for squid, although actual swimming speed may be quite different to observed movement rates due to the influence of water movements (e.g. currents). We also cannot rule out the fact that tagged squid may have been preyed upon, and the observed speeds were those of a larger predator not the squid.

Sonar and echo sounding surveys of Nototodarus gouldi have shown that they form dense aggregations close to the sea floor during the day and disperse throughout the water column at night (Evans 1986). However, on only 1 occasion in this study were more than 2 individuals caught at the same time and place. Either our catchability was extremely poor, or the squid were not forming large daytime aggregations in the study area; it may be that the numbers of $N$. gouldi during the study were below some 'threshold' for schooling behaviour. There was little evidence of positive association among individuals tagged and released together. Only a small number of individuals released in 'groups' were subsequently detected, and rarely together, except shortly after release. There was no evidence that they remained together further into the study. A lack of group fidelity throughout the study may be due to new aggregations being formed each day after nighttime dispersion. While it seems likely that squid might be found in the same region at the same time in response to external variables such as prey concentration, we would not necessarily expect them to move together over the course of the study. Sample sizes were simply too small and this study not designed to maximise information regarding such behavioural patterns; however, the potential of the automated VR2 system for elucidating school structure and behaviour is recognised.

There was no clear relationship between photoperiod (time of day) and activity inferred by the number of visit events, though the duration of visits was generally greater and far more variable during the evening than during the day. Research suggests that Nototodarus gouldi are more active and feed more during the night compared to day (O'Sullivan \& Cullen 
1983, Nowara \& Walker 1998). However, these results are confounded by the use of commercial jig boats with light attractants to obtain samples. Diurnal feeding behaviour is variable among other ommastrephid species, but it appears that they are active hunters during both the day and night, with several feeding peaks, depending on the diurnal behaviour of the prey (Haimovici et al. 1998, Quetglas et al. 1999, Laptikhovsky 2002). Variability in the duration of evening visits in this study might be explained by a combination of periods of low activity as individuals remain in an area to feed or rest, set against short visit durations indicative of active movement into and out of the range of receivers, perhaps as the squid search for prey.

The use of the automated acoustic tracking system has provided new insight into the movement and activity dynamics of the inshore Nototodarus gouldi population in southeastern Tasmania. Future research could benefit from larger samples sizes (feasible given the relatively low cost of transmitters compared to other electronic tag types), and being able to couple the individual movement data to population distribution and abundance data. The design of the receiver network in this study made it difficult to determine direction of movement, or indeed whether the tagged animal actually crossed through a curtain, unless it was subsequently detected at another curtain. In future studies, where understanding directionality is important, it could be more suitable to have double curtains, or to at least stagger the placement of receivers in a zigzag design along the line of the curtain. This would have the added benefit of reducing the size of gaps created by lost or failed receivers.

Acknowledgements. We thank all staff of the Tasmanian Aquaculture \& Fisheries Institute and volunteers who assisted with fieldwork. In particular, we thank J. Semmens, J. Stark, S. Tracey, L. Triantafillos and the crew of the FRV 'Challenger'. Two anonymous reviewers provided comments that resulted in an improved manuscript. Financial support for the study was provided by grants from the Australian Research Council (Grant DP0210373 to G.D.J. and D. Welch), the Holsworth Wildlife Research Fund Postgraduate Award (Grant L0013234 to K.E.S.) and operational support from the Tasmanian Aquaculture \& Fisheries Research Institute. This project was conducted with ethics approval (A0006997).

\section{LITERATURE CITED}

Aitken JP, O'Dor RK, Jackson GD (2005) The secret life of the giant cuttlefish Sepia apama (Cephalopoda): behaviour and energetics in nature revealed through radio acoustic positioning and telemetry (RAPT). J Exp Mar Biol Ecol 320:77-91

Arendt M, Lucy J, Munroe TA (2001) Seasonal occurrence and site-utilization patterns of adult tautog, Tautoga onitis (Labridae), at manmade and natural structures in lower Chesapeake Bay. Fish B-NOAA 99:519-527
Arkhipkin A (2000) Intrapopulation structure of winterspawned Argentine shortfin squid, Illex argentinus (Cephalopoda, Ommastrephidae), during its feeding period over the Patagonian Shelf. Fish B-NOAA 98:1-13

Basson M, Beddington JR, Crombie JA, Holden SJ, Purchase LV, Tingley GA (1996) Assessment and management techniques for migratory annual squid stocks: the Illex argentinus fishery in the Southwest Atlantic as an example. Fish Res 28:3-27

Block BA, Dewar H, Blackwell SB, Williams T and 5 others (2001) Archival and pop-up satellite tagging of Atlantic bluefin tuna. In: Sibert JR, Nielsen JL (eds) Electronic tagging and tracking in marine fisheries. Kluwer Academic, Dordrecht, p 65-88

Brill R, Lutcavage M, Metzger G, Bushnell P, Arendt M, Lucy J, Watson C, Foley D (2002) Horizontal and vertical movements of juvenile bluefin tuna (Thunnus thynnus), in relation to oceanographic conditions of the western North Atlantic, determined with ultrasonic telemetry. Fish B-NOAA 100:155-167

Clementson LA, Harris GP, Griffiths FB, Rimmer DW (1989) Seasonal and interannual variability in chemical and biological observations in Storm Bay Tasmania. I. Physics, chemistry and the biomass of components of the food chain. Aust J Mar Freshw Res 40:25-38

Comeau LA, Campana SE, Castonguay M (2002) Automated monitoring of a large-scale cod (Gadus morhua) migration in the open sea. Can J Fish Aquat Sci 59:1845-1850

Evans K (1986) Arrow squid behaviour and vulnerability to netting techniques. Department of Sea Fisheries, Tasmania, Technical Report 12, Hobart

Haimovici M, Brunetti NE, Rodhouse PG, Csirke J, Leta RH (1998) Illex argentinus. In: Rodhouse PG, Dawe EG, O'Dor $\mathrm{R}$ (eds) Squid recruitment dynamics. FAO, Rome, p 27-58

Hatfield EMC, Rodhouse PG (1994) Migration as a source of bias in the measurement of cephalopod growth. Antarct Sci 6:179-184

Heupel MR, Hueter RE (2001) Use of an automated acoustic telemetry system to passively track juvenile blacktip shark movements. In: Sibert JR, Nielsen JL (eds) Electronic tagging and tracking in marine fisheries. Kluwer Academic, Dordrecht, p 217-236

Heupel MR, Hueter RE (2002) Importance of prey density in relation to the movement patterns of juvenile blacktip sharks (Carcharhinus limbatus) within a coastal nursery area. Mar Freshw Res 53:543-550

Hooge PN, Eichenlaub B (1997) Animal movement extension to ArcView. Ver 1.1. Alaska Biological Science Center, US Geological Survey, Anchorage, AK

Jackson GD, McGrath Steer B, Wotherspoon S, Hobday AJ (2003) Variation in age, growth and maturity in the Australian arrow squid Nototodarus gouldi over time and space-what is the pattern? Mar Ecol Prog Ser 264: $57-71$

Klimley AP, Voegeli FA, Beavers SC, Le Boeuf BJ (1998) Automated listening stations for tagged marine fishes. Mar Technol Soc J 32:94-101

Laptikhovsky V (2002) Diurnal feeding rhythm of the shortfin squid Illex argentinus (Cephalopoda: Ommastrephidae) in the Falkland waters. Fish Res 1373:1-5

Lyle JM (2003) Tasmanian scalefish fishery - 2002. TAFI fishery assessment report. Tasmanian Aquaculture \& Fisheries Institute, Hobart

Lynch AW (2004) Southern squid fishery data summary 2002-2003. Logbook Program, Australian Fisheries Management Authority, Canberra

Markaida U, Rosenthal JJC, Gilly WF (2005) Tagging studies 
on the jumbo squid (Dosidicus gigas) in the Gulf of California, Mexico. Fish B-NOAA 103:219-226

McGrath BL, Jackson GD (2002) Egg production in the arrow squid Nototodarus gouldi (Cephalopoda: Ommastrephidae), fast and furious or slow and steady? Mar Biol 141:699-706

Mokrin NM, Novikov YV, Zuenko YI (2002) Seasonal migrations and oceanogaphic conditions for concentration of the Japanese flying squid (Todarodes pacificus Steenstrup, 1880) in the northwestern Japan Sea. Bull Mar Sci 71: $487-499$

Moran MJ, Burton C, Jenke J (2003) Long-term movement patterns of continental shelf and inner gulf snapper (Pagrus auratus, Sparidae) from tagging in the Shark Bay region of Western Australia. Mar Freshw Res 54:913-922

Nagasawa K, Takayanagi S, Takami T (1993) Cephalopod tagging and marking in Japan: a review. In: Okutani $T$, O'Dor R, Kubodera T (eds) Recent advances in fisheries biology. Tokai University Press, Tokyo, p 313-329

Nakamura Y (1993) Vertical and horizontal movements of mature females of Ommastrephes bartramii observed by ultrasonic telemetry. In: Okutani T, O'Dor R, Kubodera T (eds) Recent advances in fisheries biology. Tokai University Press, Tokyo, p 331-336

Nigmatullin CM, Laptikhovsky VV, Moustahfid H (2002) Brief review on the ecology of arrow squid Todarodes sagittatus (Cephalopoda: Ommastrephidae). Bull Mar Sci 71:581-590

Nowara GB, Walker TI (1998) Effects of solar day, jigging method and jigging depth on catch rates and size of Gould's squid, Nototodarus gouldi (McCoy), in southeastern Australian waters. Fish Res 34:279-288

O'Dor R (2002) Telemetered cephalopod energetics: swimming, soaring, and blimping. Integr Comp Biol 42: 1065-1070

O'Dor RK, Hoar JA, Webber DM, Carey FG, Tanaka S, Martins HR, Porteiro FM (1994) Squid (Loligo forbesi) performance and metabolic rates in nature. Mar Freshw Behav Physiol 25:163-177

O'Sullivan D, Cullen JM (1983) Food of the Squid Nototodares gouldi in Bass Strait. Aust J Mar Freshw Res 34:261-285

Parsons DM, Babcock RC, Hankin RKS, Willis TJ, Aitken JP, O'Dor RK, Jackson GD (2003) Snapper Pagrus auratus (Sparidae) home range dynamics: acoustic tagging studies in a marine reserve. Mar Ecol Prog Ser 262:253-265

Perez JAA, O'Dor RK (1998) The impact of environmental

Editorial responsibility: Otto Kinne (Editor-in-Chief), Oldendorf/Luhe, Germany gradients on the early life inshore migration of the shortfinned squid Illex illecebrosus. S Afr J Mar Sci 20:293-303

Quetglas A, Alemany F, Carbonell A, Merella P, Sanchez P (1999) Diet of the European flying squid Todarodes sagittatus (Cephalopoda: Ommastrephidae) in the Balearic Sea (western Mediterranean). J Mar Biol Assoc UK 79: 479-486

Quinn GP, Keough MJ (2002) Experimental design and data analysis for biologists. Cambridge University Press, Cambridge

Reid TA, Hindell MA (2000) Coarse-scale relationships between seabirds and zooplankton off south-eastern Tasmania. Mar Freshw Res 51:789-798

Roper CFE, Sweeney MJ, Nauen CE (1984) Cephalopods of the world, Vol 3. FAO, Rome

Sauer WHH, Roberts MJ, Lipinski MR, Smale MJ, Hanlon RT, Webber DM, O'Dor R (1997) Choreography of the squid's 'Nuptial Dance'. Biol Bull (Woods Hole) 192:203-207

Sauer WHH, Lipinski MR, Augustyn CJ (2000) Tag recapture studies of the chokka squid Loligo vulgaris reynaudii d'Orbigny, 1845 on inshore spawning grounds on the south-east coast of South Africa. Fish Res 45:283-289

Triantafillos L, Jackson GD, Adams M, McGrath Steer B (2004) An allozyme investigation of the stock structure of arrow squid Nototodarus gouldi (Cephalopoda: Ommastrephidae) from Australia. ICES J Mar Sci 61:829-835

Voegeli FA, Lacroix GL, Anderson JM (1998) Development of miniature pingers for tracking Atlantic salmon smolts at sea. Hydrobiologia 371/372:35-46

Watanabe H, Kubodera T, Ichii T, Kawahara S (2004) Feeding habits of neon flying squid Ommastrephes bartramii in the transitional region of the central North Pacific. Mar Ecol Prog Ser 266:173-184

Welch DW, Boehlert GW, Ward BR (2003) POST — the Pacific Ocean salmon tracking project. Oceanol Acta 25:243-253

Willcox S, Lyle J, Steer M (2001) Tasmanian arrow squid fishery - status report 2001. Tasmanian Aquaculture and Fisheries Institute, Hobart

Winstanley RH, Potter MA, Caton AE (1983) Australian cephalopod resources. Mem Natl Mus Vic 44:243-253

Yoshida M, Baba T, Kiyota M, Koido T (1990) Behavioural study of flying squid by an ultrasonic telemetry. In: Japanese society of fisheries oceanography (ed) Abstracts of symposium of squid resources and its use. p 5-8 (in Japanese) (cited in Nakamura Y 1993)

Submitted: June 3, 2004; Accepted: March 31, 2005

Proofs received from author(s): August 1, 2005 